\title{
Dynamical response of railway switches and crossings
}

\author{
Vlastislav Salajka ${ }^{1}$, Marek Smolka ${ }^{2}$, Jiř́ Kala ${ }^{1,{ }^{*}}$ and Otto Plášek ${ }^{3}$ \\ ${ }^{1}$ Brno University of technology, Dept. of Structural Mechanics, 60200 Brno, Czech Republic \\ ${ }^{2}$ DT - Vyhybkarna a strojirna, a.s., Dolni 3137/100, Prostejov, Czech Republic \\ ${ }^{3}$ Brno University of technology, Dept. of Railway structures, 60200 Brno, Czech Republic
}

\begin{abstract}
A procedure for the numerical analysis of the dynamic response during the passage of railway vehicles is described. The solution is based on the finite element method (FEM), which is used for the calculation of track stresses. An FEM model was used with a fine structure that included all components of switches and crossings, including movable parts. The excitation forces are defined on the basis of the assumed interaction between track and vehicle. The track stiffness defined by FEM analyses is used for the calculation of dynamic vertical and lateral wheel load. A special model of a railway vehicle was built with the aim of calculating the forces at points where abrupt stiffness changes occur, as well as geometrical imperfections in the frog structure.
\end{abstract}

\section{Introduction}

Switches behaviour optimization from the perspective of reduction of the responses of dynamic effects during vehicles passages brings the need for creation of comprehensive computational geometrically complex models with an appropriate degree of simplification. Numerical solutions using mathematical models created in the finite element method (FEM) comprise a turnout superstructure and substructure including structural layers. The 3D models are demanding in terms of boundary conditions (loads and bonds) modelling and parameters definition [1]. It is necessary to use suitable material models. Results obtained with the aid of these complex models allow a detailed analysis of an individual component of the turnout without the need to introduce considerable simplification $[2,3]$.

All the details of models require an application of an appropriate program at appropriate work-stations that can compute with enormous data files. The solution is also demanding both for computing time and storage space. A high level of expertise as well as routine knowledge of the applied program is required. Despite the stated demands, obtaining the searched results is virtually practicable.

The issue of finding a feasible design of a rail fastening in the turnout is the subject matter of a turnout with an increased elasticity of track. Searching for the optimal switches arrangement design is based on numerical analyses of the specified J60-1:12-500 turnouts including the analyses of the individual rail fastening of the turnout with corrections related

\footnotetext{
*Corresponding author: kala.j@ffce.vutbr.cz
} 
to the experiment [4]. The FEM are used in which detailed global numerical models of the turnout are created is applied for the calculation. The verified rail fastening using the partial FEM models are put into the global models of the switches on which the dynamic analysis of the vehicle travel effect was carried out. Alternative solutions of responses provided a possibility to determine a suitable solution of the structural arrangement in terms of the strength and the dynamic behaviour with the aim of the turnout life extension.

\section{Computation model}

The computational turnout model is created by the finite element method in the ANSYS software system. The primary geometry of the turnout model was taken from a 3D CAD model in a SAT format and extended by an access and outgoing part formed by a track length of a plain track from the both sides. The computational model consists of a range of element types. Three-dimensional parts (rails, a crossing, switch tongues, sleepers and bearers, elastic bedding compensating the road bed stiffness and some steel parts of the bedding and rail pads) are modelled by three-dimensional eight-node finite elements. Trough sleepers, base plates and slide plates in the turnout, elements carrying a check rail are modelled by four-node shell elements.

The check rail is modelled in a simplified way by general beam elements. Fastening clamps are modelled in a simplified way by beam elements only carrying axial forces. Additional weight of an electromotor point machine was compensated by concentrated mass on the trough sleeper face modelled by a one-node element. These elements are attached by auxiliary beam elements so that the location of the mass centre of gravity would be maintained. The elastic bedding reflecting road bed subgrade is modelled by four-node surface elements. The final element model is shown in the Figure 1. A great attention was paid to the modelling of the rail fastening and the rail bedding, especially in the switch part. In the rail fastening, with the base plates in the turnout as well as without base plates in the plain track, rail fastening Vossloh types were used [5]. Clamp stiffness characteristics are defined by work diagrams. Clamp modelling is carried out by special elements that have the vertical stiffness. The preload to the clamps is brought by a set value of the relative axial deformation $\varepsilon_{\mathrm{ax}}$ of the clamp.

Between the rail and the sleeper, there is a layer modelled that varies according to the rail fastening point. The material used for the rail pads is rubber that is characterized by the non-linear behavior. The vertical stiffness of the rail pads in relation to the rate of loading is verified experimentally. The static and dynamic stiffness of the rail pads is distinguished by this $[6,7]$.

The values of the modulus characterize the stiffness under the dynamic stress of the track and they are selected so that the relative deflection during the travel would correspond to the real values. The two lower layers are coated by elastic plane elements that reflect the stiffness of the surroundings. The stiffness values control the deflection of the railway line model. At an alternative solution the $k_{W}$ values are changed in relation to the solved alternative. In cross-sections at the ends of the model (a rail and bedding layers section), there are boundary conditions limiting the normal displacement to the given section. There are boundary conditions limiting the horizontal displacement in the lower model level in all the nodes. It should also be mentioned that the tongue ends bear on the rail at the distance of $1.5 \mathrm{~m}$. This contact is modelled by an order of the common displacement of the tongue and rail nodes in the horizontal lateral direction. 
The rail fastening on the two steel trough sleepers remains without additional elasticity. The modified model of the track with the additional elasticity consists of 407 thousand elements that are located by 522 thousand nodes and it has almost 1.5 mil degrees of freedom, Fig. 1.
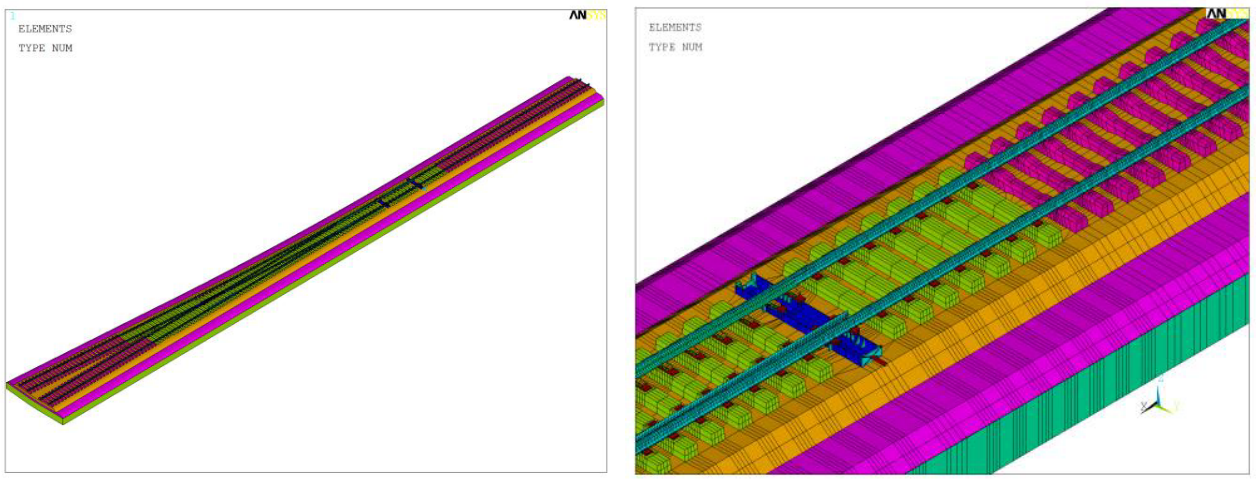

Fig. 1. Computational model.

The stiffness of the turnout running parts varies in relation to the method of their fastening and depending on the stiffness of base courses under the sleepers. Several areas where the rail fastening stiffness varies significantly are considered. The first region that is included in the model is the region in front of the switch. The rails are fastened on the B $91 \mathrm{~S}$ sleepers here. It is a standard rail fastening W14 type on the sleepers in the ballast bed. The same applies to the region of the model behind the switch. The turnout structure can be divided into the area in front of the switch, a switch part, a middle part, a crossing part and the area behind the switch. Rail bedding additional elasticity is designed in the switch and crossing parts. In the switch part the additional elasticity is at 40 places and in the crossing part it is at 9 places. A slide plate with a pressure spring clip is designed for the switch part. The slide plate structure allows a vertical movement of the sliding surface (a place where the tongue is supported). The model of switch additional elasticity corresponds to the real version. The additional elasticity in the model under the crossing is simply carried out by the pad stiffness modification. The model in the area of the tongue tip is shown in the Fig. 2 where the differences in modelling of the slide plates under the tongues can be seen.

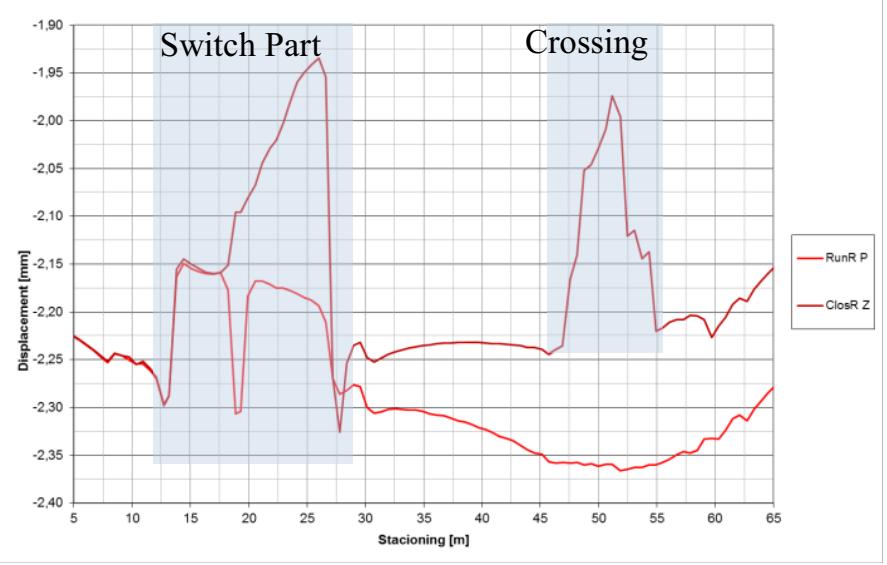

Fig. 2. Deflection of rails with standard rail fastening. 
The check of the individual rail fastening in the global model was carried out on partial computational models of the fastening system. Parts of the model were separated from the turnout global model and modified so that they would correspond to the test fastening. Then the elastic layer stiffness in the model was reiteratively determined so that the vertical stiffness of the model fastening is in accordance with the dynamic stiffness obtained from the test.

At the same time, solving the dynamic responses with a model of a vehicle is possible, but at such a great extent of the turnout model virtually impossible. To simplify, the interaction between the vehicle and the running rail of the turnout is substituted by the dynamic force effects that consider discontinuities in the stiffness of the rail track, the impact of the turnout part wear and deficiencies in the rail geological base. The force effects including the static and dynamic parts are represented by a couple of forces, the conducting lateral force $Y$ and the vertical wheel load $Q$, whose intensity varies in relation to the travelling speed, the rail geometry and the vehicle type.

For the each solution alternative of the vehicle travel through the turnout, the dynamic stiffness of the travel route need to be determined. It is about obtaining stiffness influence lines of the rail head deflection in the discrete points of the FEM model from the static states under the action of the two wheel loads, each of the selected intensity.

\section{Dynamic analyses}

The static calculations are performed for the monitored alternatives of the structural layers stiffness. After the performance of the loading states calculation with a change of the wheel loads location, a state including the preload influence in the rail fastening has to be subtracted from the each state [8].

Interactions between an eight-wheel vehicle and the track length are determined by a simulative calculation using the influence lines. The calculation of the interaction forces continues on the cooperation with the employees of the University of Pardubice, which deals with vehicle travel simulations. At that workplace, response of the selected vehicle with the set speed and assumed characteristics of the track is determined from the behaviour of dynamic stiffness [9].

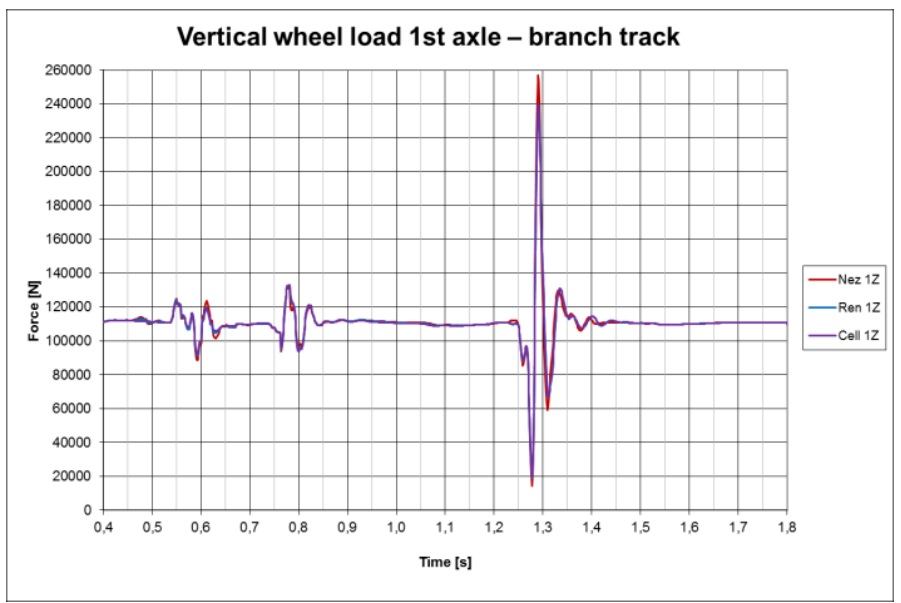

Fig. 3. Vertical wheel load 1 st axle - branch track.

The wheel forces obtained like this acting retroactively on the heads of the rails are further used as excitation loading with a variable position corresponding to the travelling 
vehicle with the specified speed, see the Fig. 3. The dynamic response calculations are carried out by direct integration of equations of motion. The results include a displacement field, deformation and stress in individual instants of time of the solution. Alternations in all the modelled parts of the turnout as well as other design elements can be monitored this way. The static analysis indicates the differences in the turnout stiffness during the passage either in a straight or branch direction, from which suitability or unsuitability of the design of the rail fastening nodes arrangement can be deduced.

The increase of the deflections (see the Fig. 4) and forces in dynamically influenced areas and the endurance strength for the judgement of the endurance of the fastening structure and other derived values, such as speed and acceleration fields, can be read from the dynamic response. This allows you to monitor and to analyse the impact of design changes on the turnout behaviour.

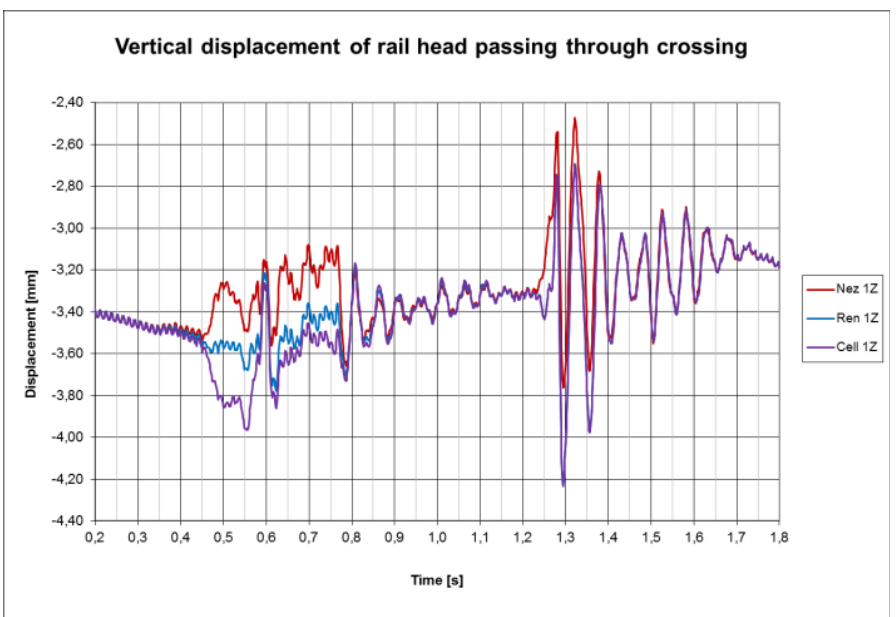

Fig. 4. Dynamic response - vertical displacement of rail head passing through crossing.

\section{Conclusions}

The calculations of the turnout dynamic response to the passage of the railway eight-wheel vehicle through the turnout in the straight direction against the tongue tip were carried out. There were three alternatives distinguished. The alternative with the original arrangement of the rail bedding, the tongue and the crossing and two alternatives with designed additional elasticity of the track in the switch and in the crossing. The elasticity in the switch part was considered in the alternative of the "suitable" elasticity and in the "soft" alternative. In the crossing part the elasticity is identical for the both elastic alternatives.

It can be concluded that with the aid of the calculations it was not found that the elasticity creates unexpected changes in the displacement and the force action in the turnout structure. On the basis of the performed calculations we can observe that the passage through the turnout with elasticity is smoother and it is more balanced while passing through the switch and the crossing in comparison to the original alternative without elasticity. The extreme stresses in all components of permanent way occur in switches and crossings during a passage of railway vehicles. The additional dynamic loading originates from changes in the track stiffness along the railway turnout or alternatively impact forces cause at points of geometry imperfections. The stresses can be reduced due to the control of track stiffness by using rail fastening with different elasticity of rail pads or special elastic pads in slide plates in switches [10]. 
This outcome has been achieved with the financial support of project GACR 17-23578S "Damage assessment identification for reinforced concrete subjected to extreme loading" provided by the Czech Science Foundation and under the project No. LO1408 "AdMaS UP - Advanced Materials, Structures and Technologies”, supported by Ministry of Education, Youth and Sports under the „National Sustainability Programme I" and with the financial support of the project FAST-S-16-3718 "Advanced numerical methods with complex material models" provided by the Brno University of Technology fund for specific university research.

\section{References}

1. P. Král, P. Hradil, J. Kala, F. Hokeš, M. Hušek, Identification of the Parameters of a Concrete Damage Material Model, Procedia Engineering, 172, 578-585 (2017)

2. J. Kala, M. Hušek, High Speed Loading of Concrete Constructions with Transformation of Eroded Mass into the SPH, International Journal of Mechanics, 10, 145-150 (2016)

3. Z. Kala, J. Valeš Global Sensitivity Analysis of Lateral-torsional Buckling Resistance Based on Finite Element Simulations, Engineering Structures, 134, 37-47 (2017)

4. V. Salajka, et al.. Simulation of a vehicle passage over the turnout with an additional realistic elasticity of rail fastening and with the crossing of a new design (Research Report for DT - Výhybkárna a strojírna, a.s., 45 pp. 2014)

5. C. Esveld, Modern Railway Track ( $2^{\text {nd }}$ Ed. Delft, MRT - Production, 2001)

6. J. Kala, M. Hušek, Improved Element Erosion Function for Concrete-like Materials with the SPH Method, Shock and Vibration, 2016, 1-13 (2016)

7. F. Hokes, J. Kala, Selecting the objective function during the inverse identification of the parameters of a material model of concrete, Frattura ed Integrita Strutturale, (Fracture and Structural Integrity), 11 (39), 7-16, (2017)

8. V. Salajka, V. Kanický, Track Response to Traffic Load Using Non-linear Computing Model. Proceedings Traffic Applied Mechanics'99, University Pardubice,15-20. (1999)

9. P. Král, P. Hradil, J. Kala, Inverse Identification of the Material Parameters of a Nonlinear Concrete Constitutive Model Based on the Triaxial Compression Strength Testing, Frattura ed Integrità Strutturale (Fracture and Structural Integrity), 11 (39), 3846, (2017)

10. W. Stahl, Untersuchung eines für HGV optimierten Schotteroberbaus. Querverschibewiederstandmessungen und Schwingungsverhalten. Der Eisenbahningenieur, 5, 8-16, (2003) 